\title{
EIS AND SKP STUDY ON IMPROVEMENT OF THE PROTECTION PERFORMANCE OF AN ALKYD-VARNISH COATING MODIFIED WITH AIR-PLASMA TREATMENT ON Q235 STEEL
}

\author{
EIS IN SKP ŠTUDIJA IZBOLJŠANJA ZAŠČITE Z ALKIDNO \\ PREVLEKO, MODIFICIRANO S PLAZEMSKO OBDELAVO NA \\ Q235 JEKLU
}

\author{
Chuanbo Zheng ${ }^{1}$, Haoyang $\mathrm{Qu}^{1}$, Wei Wang ${ }^{2}$ \\ ${ }^{1}$ Jiangsu University of Science and Technology, School of Materials Science and Engineering, Mengxi Road 2, Zhenjiang, Jiangsu Province, \\ 212003, China \\ ${ }^{2}$ State Key Laboratory for Marine Corrosion and Protection, Luoyang Ship Material Research Institute (LSMRI), 149-1 Zhuzhou Road, \\ Laoshan District, Qingdao, 266101, China \\ 15952802516@139.com
}

Prejem rokopisa - received: 2017-02-16; sprejem za objavo - accepted for publication: 2017-05-30

doi:10.17222/mit.2017.022

Electrochemical impedance spectroscopy (EIS) and scanning Kelvin probe (SKP) were used to study the failure of the coating modified with air-plasma treatment in $3.5 \%$ mass fraction of $\mathrm{NaCl}$. The results show that the failure process can be divided into three stages including water penetration, accumulation of corrosion products at the location of a defect, water penetration of the entire coating and coating failure. The EIS results show that the plasma-treated samples exhibit an additional electrical double-layer capacitor that delays the coating failure during the second stage. The potential of the non-plasma-treated samples decrease faster than that of the plasma-treated samples according to the SKP study. As the transition layer, air plasma delays the coating failure due to the chemical bond between the metal substrate and the coating.

Keywords: air-plasma treatment, electrochemical impedance spectroscopy, scanning Kelvin probe, coating failure, hydrostatic pressure

Elektrokemijsko impedančno spektroskopijo (angl. EIS) in vrstično Kelvinovo sondo (SKP) smo uporabili za preučevanje poškodb na prevleki, modificirani s plazmo, v 3,5 mas. \% raztopini $\mathrm{NaCl}$. Rezultati kažejo, da se nastajanje poškodb lahko razdeli na tri faze, vključno s penetracijo vode: na akumulacijo korozijskih produktov na mestu napake, na prodiranje vode $\mathrm{v}$ dele celotne prevleke in na odpoved prevleke. Rezultati EIS kažejo, da imajo vzorci, obdelani v plazmi, dodaten električni dvoslojni kondenzator, ki v drugi fazi upočasni poškodbo prevleke (premaza). SKP-analize so pokazale, da se potencial plazemsko neobdelanih vzorcev zmanjšuje hitreje kot tistih vzorcev, ki so bili obdelani s plazmo. Kot prehodna plast, obdelava z zračno plazmo upočasni poškodbo premaza zaradi kemijske vezi med kovinskim substratom in prevleko.

Ključne besede: obdelava s plazmo, elektrokemijska impedančna spektroskopija, skeniranje s sondo Kelvin, odpoved prevleke, hidrostatični tlak

\section{INTRODUCTION}

With the exploration and development of marine research, problems of the corrosion and protection of structural materials and organic coatings in marine environments have increasingly gained attention. ${ }^{1-3}$ Thus, the corrosion problems of the materials under deep-ocean conditions must be considered. The environment of the deep ocean is a complicated system, including hydrostatic pressure, differently dissolved oxygen (DO), all kinds of salts, water velocity and suspended silt. Coating deterioration, delamination, blistering and penetration are likely to occur in the deep-sea environment. ${ }^{4-6}$ How to improve the coating quality is an urgent need for deep-ocean resource exploitation.

Due to the fact that air-plasma treatment ${ }^{7-10}$ does not alter the overall performance of the substrate, the chemical and physical activities of a material surface remains constant. During a reaction, polar oxygen groups with single or double bonds can be incorporated into the surface of the substrate, enhancing the wettability of the substrate surface. ${ }^{11,12}$ After the air-plasma treatment, the hydrophobicity and spreading ability of the material surface were also found to improve. In addition, porosity is effectively reduced on the substrate surface due to a better wettability of the organic coating. Therefore, the coating in combination with the surface of the substrate allows a better modification process. ${ }^{7,8,13}$

Many researchers effectively modified surfaces with plasma-processing techniques in order to increase hydrophobicity and alter only the surface properties of the material. L. Wang et al. ${ }^{14}$ prepared a column-like nano/ micro-scale topography surface via trichloro(octyl)silane (TCOS) vapor deposition on a polydimethylsiloxane oxidized with air plasma. Their results showed a successful assembly of TCOS on a polydimethylsiloxane surface. An addition of n-heptanol to alkylsiloxane also helps regulate the scale and roughness of the column-like nano/micro-scale topography. C. Riccardi et al. ${ }^{15}$ induced 
C. B. ZHENG et al.: EIS AND SKP STUDY ON IMPROVEMENT OF THE PROTECTION PERFORMANCE ...

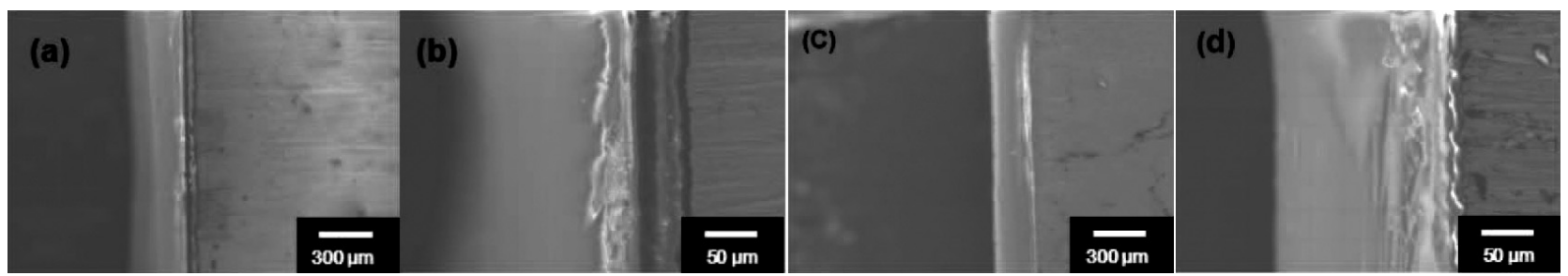

Figure 1: Cross-sections of alkyd-varnish coatings with and without plasma treatment; a), b): with plasma treatment; c), d): without plasma treatment

chemical and physical surface modifications of poly (ethylene terephthalate) fibers using radio-frequency air-plasma treatments. After the treatment, the fibers demonstrated significant increases in hydrophilicity, accompanied by extensive etching and an incorporation of both polar oxygen- and nitrogen-containing groups. Air-plasma treatment was applied extensively and with excellent results when treating organic compounds. However, the cases of the air-plasma treatment being applied to metal substrates are rare.

In this work, for the transition layer, air-plasma treatment was performed on a metal surface. The effect of the plasma treatment on the failure process of alkyd-varnish coatings (AVCs) with defects under deep-ocean conditions was investigated. EIS ${ }^{16-19}$ and SKP ${ }^{20-24}$ were used as electrochemical macroscopic and microscopic characterization methods, respectively. The depth-from-defocus method was also applied as an intuitive approach to observing the changes in the defects and the coating.

\section{EXPERIMENTAL PART}

\subsection{Materials}

The Q235 carbon steel was produced by Shanghai BaoSteel. The water used in all the experiments was produced by the Milli-Q plus 185 purification system. Q235 carbon-steel samples with dimensions of $1 \mathrm{~cm} \times$ $1 \mathrm{~cm} \times 1 \mathrm{~cm}$ were used as substrates and sealed with epoxy resin. The substrates were first ground with 400-1200-grade SiC paper, degreased ultrasonically in acetone and rinsed with double-distilled water.

Some samples were treated with air plasma and the reactor employed for the plasma treatment was APJD-1000. The alkyd varnish was applied to the substrate surface with a controlled thickness of approximately $50 \mu \mathrm{m}$, using the roller-coating method. The coatings were then dried in air and pinholes were formed in the center of the coatings with a needle whose diameter was $100 \mu \mathrm{m}$, using a friction-and-wear machine.

Figure 1 shows the cross-sections of the specimens prepared with ( $\mathrm{a}$ and $\mathrm{b}$ ) and without (c and d) air-plasma treatment.

\subsection{Experiment condition}

To simulate a 450-meter deep-sea condition of low temperature and low oxygen, an autoclave corrosiontesting machine of SSRT (constant load, low-cycle fatigue) produced by Cortest Inc. was adopted in the experiment. The hydrostatic pressure in the reactor was 4.5 $\mathrm{MPa}$, the temperature in the reactor was controlled to be $10 \pm 2{ }^{\circ} \mathrm{C}$, and the content of dissolved oxygen in water was controlled to be $4.0 \pm 0.5 \mathrm{mg} / \mathrm{L}$, using the oxygen-concentration detector included in the equipment.

\subsection{Experimental techniques}

\subsubsection{Depth-from-defocus method}

To observe the process of the coating failure from an optical point of view, the depth-from-defocus method was adopted using a KH-8700 digital microscope produced by HIROX Co. Ltd. (Tokyo, Japan). Every sample was observed in the mid-range with a $140 \times$ magnification.

\subsubsection{Electrochemical measurements}

Bipotentiostat PGSTAT302N Metrohm Autolab was used for the EIS measurements. The EIS measurements were carried out using a conventional three-electrode cell. The working-electrode area was $1 \mathrm{~cm}^{2}$. A saturated calomel electrode (SCE) and a platinum wire were employed as the reference and counter electrodes, respectively. An aqueous solution with a $3.5 \%$ mass fraction of $\mathrm{NaCl}(\mathrm{pH}=7)$ prepared with ultrapure water and reagent-grade chemicals was used as the electrolyte. All the experiments were conducted at room temperature and $\mathrm{N}_{2}$ was bubbled through the electrolyte for $30 \mathrm{~min}$ before the testing and during the experiment.

Prior to impedance measurements, the open-circuit potential (OCP) was measured. When the fluctuation of the OCP was less than $500 \mu \mathrm{V}$ over a period of $60 \mathrm{~s}$, the OCP was considered to be in a stable state, allowing the EIS measurement to be carried out. Frequencies between $100 \mathrm{kHz}$ and $10 \mathrm{mHz}$ were used, with the amplitude signal set to $10 \mathrm{mV}$ to guarantee a linear response.

VersaSCAN, produced by Princeton Inc. (USA), was used for the SKP measurements. During the experiments, the working electrode must be parallel to the workbench and kept level at a distance of $100 \mathrm{~nm}$ from the probe. The probe scans two dimensions $(X$ and $Y$ ) in the range of $0-4000 \mu \mathrm{m}$ relative to the point of origin. The pinhole was located at the center of the scanning scope. In addition, the scanning steps of the $X$ and $Y$ axes were $200 \mu \mathrm{m}$ and $400 \mu \mathrm{m}$, respectively. 


\section{B. ZHENG et al.: EIS AND SKP STUDY ON IMPROVEMENT OF THE PROTECTION PERFORMANCE ...}

\section{RESULTS AND DISCUSSION}

\subsection{Coating-failure morphology observed with the depth-from-defocus method}

Figures 2 and $\mathbf{3}$ show the coating-failure process with and without air-plasma treatment. An accumulation of corrosion products in the pinhole and an increase in the area of disbonding over time were observed. However, the corrosion production volume and the disbonding area of the plasma-treated sample were smaller than those of the non-plasma-treated sample. Therefore, the protection performance of the alkyd varnish was improved with air-plasma treatment.

\subsection{EIS}

The EIS measurements of the coatings at different immersion times were important for evaluating the conditions of the coatings. Using the EIS spectra for each immersion time, we were able to divide the coating-failure process into several stages and fit electrical circuits (EC) in order to analyze this process.

The coating-failure process of the non-plasma-treated samples with a pinhole can be divided into three stages: water penetration and accumulation of corrosion products located at the defect (Figure 4a to $4 \mathbf{c}$ ), water penetration of the overall coating (Figure $\mathbf{4 d}$ to $\mathbf{4 f}$ ) and coating failure (Figure $\mathbf{4 g}$ to $\mathbf{4 i}$ ). There are two time con-
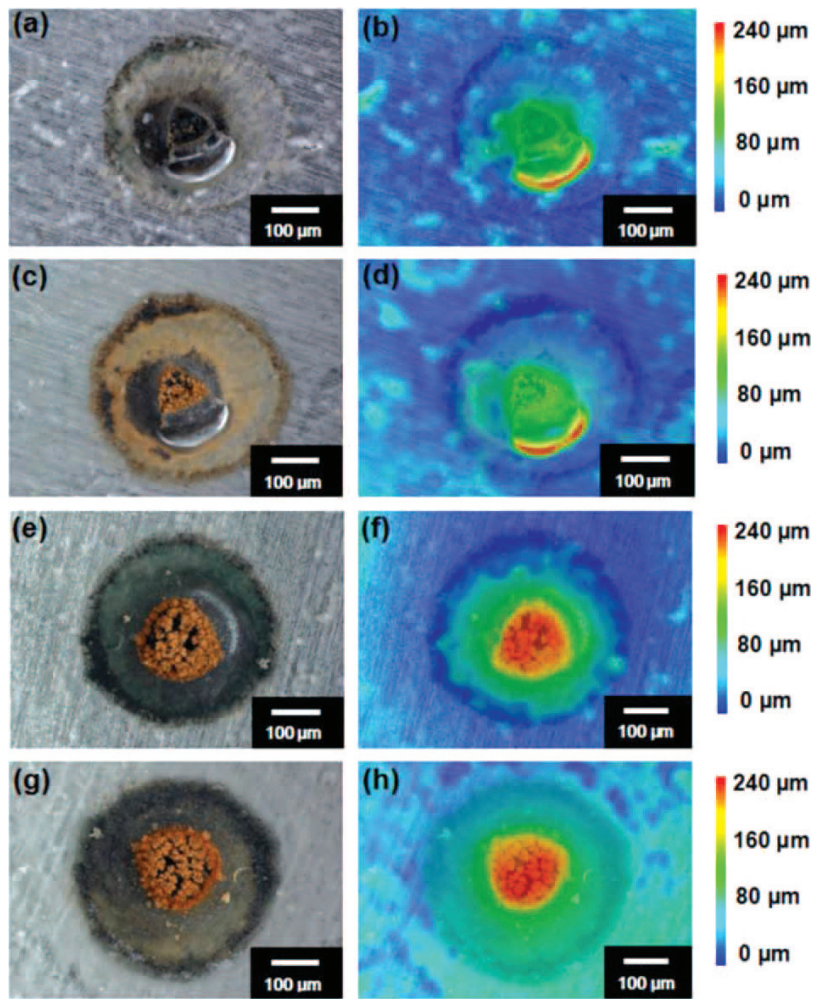

Figure 2: Photos made with the depth-from-defocus method showing the development of the coating failure for non-plasma-treated Q235 steel with crevice AVCs; photos b), d), f), and h) show the contour maps corresponding to photos a) $12.5 \mathrm{~h}$, c) $26.5 \mathrm{~h}$, e) $68.5 \mathrm{~h}$, and g) $102.5 \mathrm{~h}$, respectively stants in the first stage (Figure 4a to $\mathbf{4 c}$ ) corresponding to the small capacitive loop at high frequencies and the big capacitive loop at medium frequencies. The small and big capacitive loops serve as electrical double-layer capacitors between the coating and the solution and between the coating and the surface of the metal, respectively. In this stage, due to adequate coating protection, water penetration is effectively blocked and the numerical value of $|\mathrm{Z}|_{f=0.01}$ is large. Moreover, water can penetrate easily to the metal substrate because of the pinhole, allowing the formation of an electrical double-layer capacitor between the coating and the metal, causing corrosion to occur along the defect. Consequently, the value of $|Z|_{f=0.01}$ declines from $8 \mathrm{M} \Omega$ $\mathrm{cm}^{2}$ to $1 \mathrm{M} \Omega \mathrm{cm}^{2}$.

In the second stage, there were also two time constants corresponding to the electrical double-layer capacitors between the coating and the solution and between the coating and the surface of the metal, respectively (Figures $4 \mathbf{d}$ to $\mathbf{4 f}$ ). However, accumulation of the corrosion products at the defect blocks its ability to serve as a transport channel for water causing the value of $|Z|_{f=0.01}$ to increase to approximately $8 \mathrm{M} \Omega \mathrm{cm}^{2}$. In this process, water transport only occurs slowly through micropores in the coatings. These results indicate that there is a large Warburg diffusion coefficient occurring during the second stage.
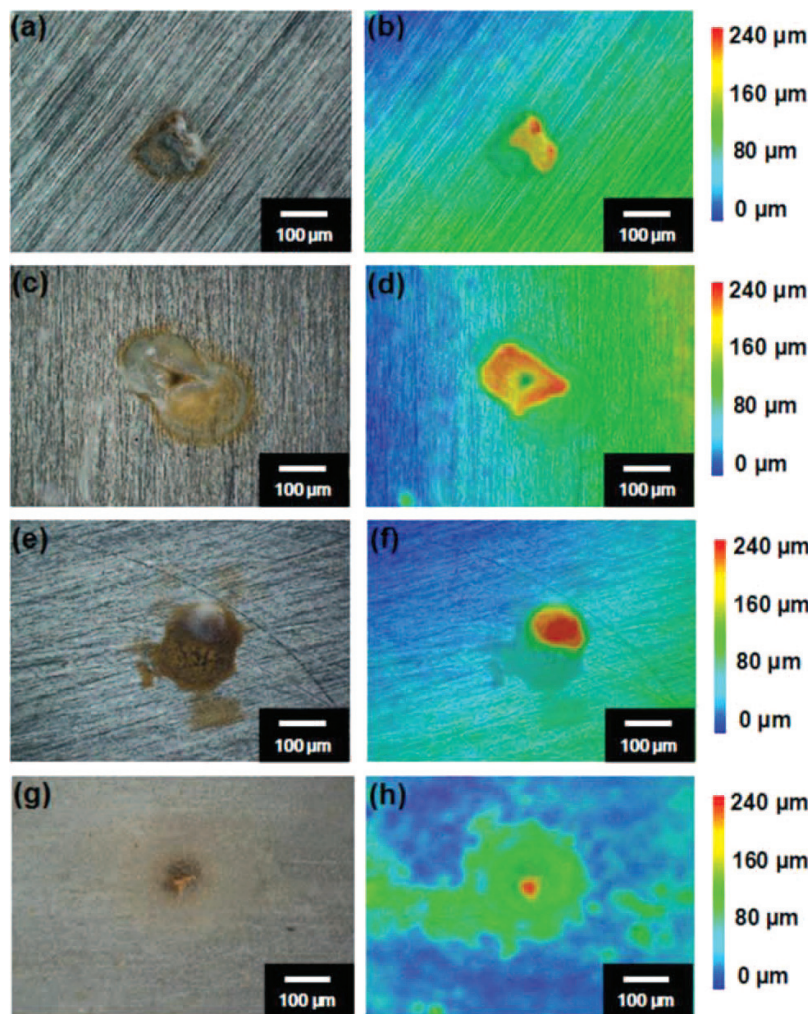

Figure 3: Photos made with the depth-from-defocus method showing the development of the coating failure for plasma-treated Q235 steel with crevice AVCs; photos b), d), f), and h) show the contour maps corresponding to photos a) $13 \mathrm{~h}$, c) $36.5 \mathrm{~h}$, e) $98 \mathrm{~h}$, and g) $143 \mathrm{~h}$, respectively 

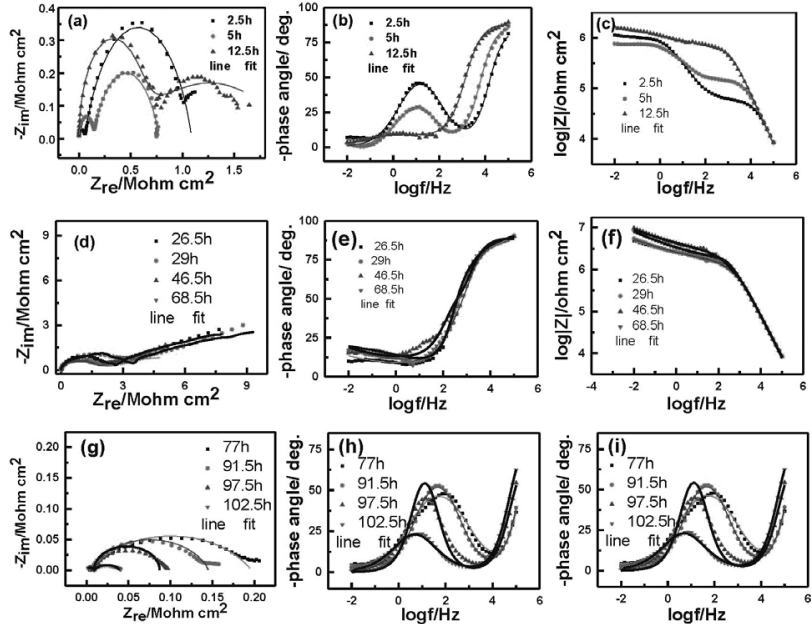

Figure 4: Nyquist and Bode plots of non-plasma-treated Q235 steel with crevice AVCs and different immersion times in a $3.5 \% \mathrm{NaCl}$ solution. The stages of the coating failure for non-plasma-treated samples include water penetration and accumulation of corrosion products located at the defect $(\mathrm{a}, \mathrm{b}$, and $\mathrm{c})$, water penetration of the overall coating (d, e and $\mathrm{f}$ ) and coating failure ( $\mathrm{g}, \mathrm{h}$ and $\mathrm{i})$.

In the third stage, continued water transport though the micropores of the coatings causes them to grow, allowing additional water transport to the surface of the metal and causing the Warburg diffusion coefficient to disappear (Figure $\mathbf{4 g}$ to $\mathbf{4 i}$ ). In this stage, local cathodic disbonding appears between the coatings and the metal substrate and the value of $|Z|_{f=0.01}$ decreases rapidly below $0.1 \mathrm{M} \Omega \mathrm{cm}^{2}$.

The coating-failure process of a plasma-treated sample with a pinhole can also be divided into three stages. The two time constants in the first stage (Figure 5a to 5c) correspond to the electrical double-layer capacitors between the coating and the solution and between the
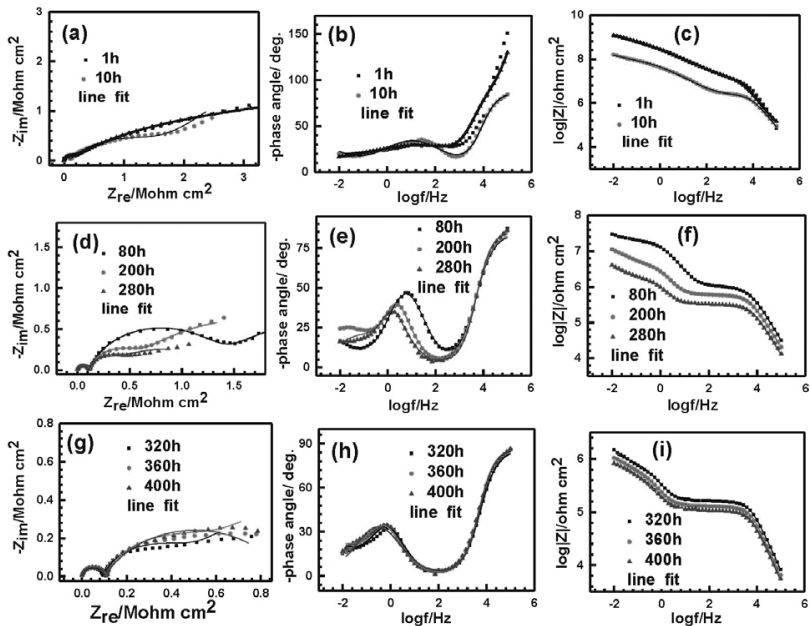

Figure 5: Nyquist and Bode plots of air-plasma-treated Q235 steel with crevice AVCs and different immersion times in a $3.5 \% \mathrm{NaCl}$ solution. The stages of the coating failure for plasma-treated samples include water penetration and accumulation of corrosion products located at the defect $(a, b$, and $c)$, water penetration of the overall coating (d, e, and f), and coating failure ( $g, h$, and $i)$. coating and the surface of the metal. The Warburg diffusion coefficient impedes the electron transport at the interface of the metal and the coatings. In this stage, an adequate protection of the coating effectively blocks water penetration and the value of $|Z|_{f=0.01}$ is large. However, the presence of the pinhole allows water to penetrate easily to the metal substrate and form an electrical double-layer capacitor between the coatings and the metal, causing corrosion to occur along the defect.

During the second stage, water begins to gradually permeate along the microporous coatings to the metal oxide layer. There are three time constants associated with this stage (Figure 5d to 5f) that correspond to the electrical double-layer capacitors of the water and the coatings, the coatings and the plasma layer, and the plasma layer and the metal substrate. The increase in the corrosion products at the defect effectively blocks the water transport and increases the value of $|Z|_{f=0.01}$.

In the third stage (Figure $\mathbf{5 g}$ to $\mathbf{5 i}$ ), the coatings lose nearly all of their protection efficiency with continued water transport and the value of $|Z|_{f=0.01}$ also decreases below $1 \mathrm{M} \Omega \mathrm{cm}^{2}$. However, the protection of the metal oxide film causes the $|Z|_{f=0.01}$ value to decrease relatively slowly. We therefore conclude that the metal oxide film can inhibit the coating failure and corrosion of the metal substrate.

The impedance data was fit with suitable equivalent circuit models to explain different electrochemical processes occurring at the electrode-electrolyte interface.
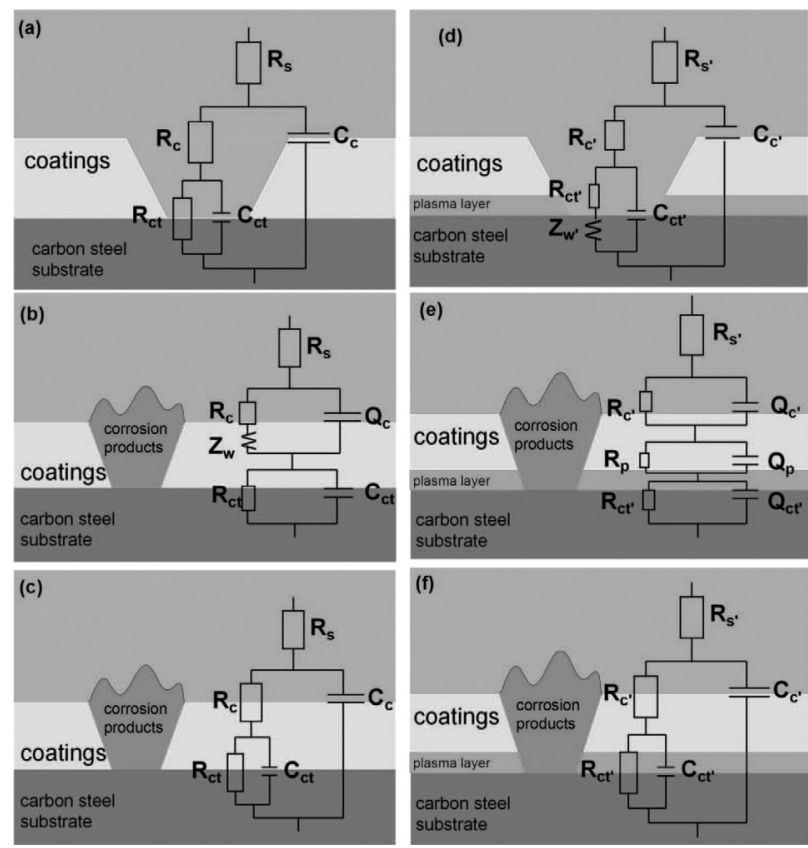

Figure 6: Equivalent circuit models used to fit the experimental impedance data of non-plasma-treated $(a, b$ and $c)$ and plasma-treated (d, e and f) Q235 steel with crevice AVCs. The three stages (water penetration and accumulation of corrosion products located at the defect, water penetration of the overall coating and coating failure) of the coating failure for non-plasma- and plasma-treated samples are shown in a-c and $\mathrm{d}-\mathrm{f}$. 

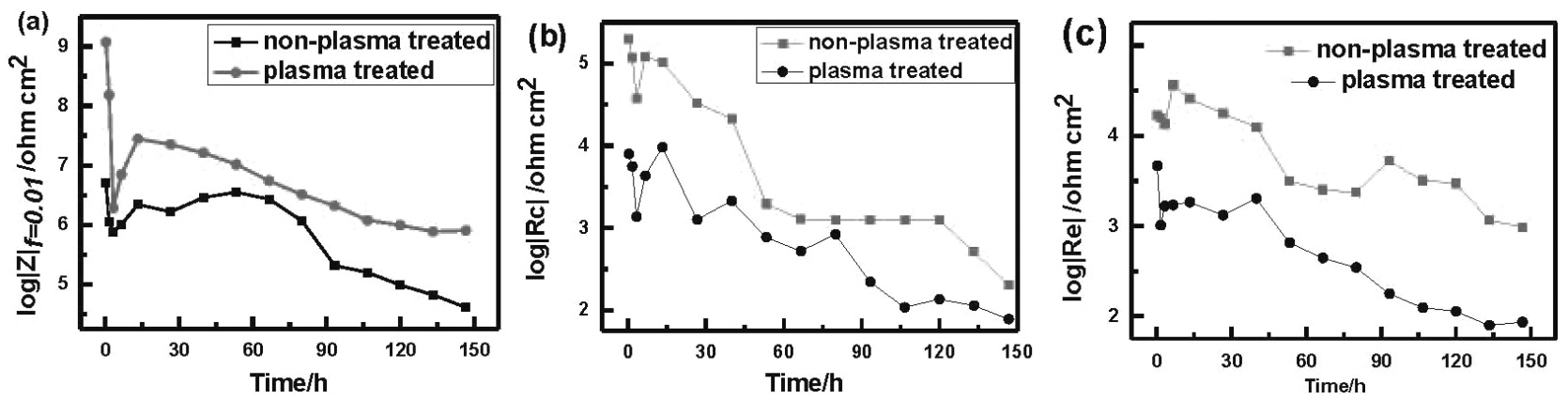

Figure 7: Change in $|\mathrm{Z}|_{f=0.01}, R_{\mathrm{c}}$ and $R_{\mathrm{e}}$ values (a, b and c, respectively) of plasma- and non-plasma-treated Q235 steel with crevice AVCs over time

The proposed electrical circuits (EC) are presented in Figure 6, showing that the model results significantly resemble the experimental data where $R_{\mathrm{s}}$ and $R_{\mathrm{s}}$ ' are the resistances of the $\mathrm{NaCl}$ electrolyte solution for the non-plasma- and plasma-treated samples, respectively; $R_{\mathrm{c}}$ and $R_{\mathrm{c}}$ ' are the coating resistances of the non-plasmaand plasma-treated samples, respectively; $R_{\mathrm{ct}}$ and $R_{\mathrm{ct}}{ }^{\prime}$ are the metal charge-transfer resistances of the non-plasmaand plasma-treated samples, respectively; $R_{\mathrm{p}}{ }^{\prime}$ is the resistance of the plasma layer; $C_{\mathrm{c}}$ and $C_{\mathrm{c}}$, are the electrical double-layer capacitances of water and coatings of non-plasma and plasma treated samples, respectively; and $C_{\mathrm{ct}}$ and $C_{\mathrm{ct}}$ are the electrical double-layer capacitances of the metal charge transfer of the non-plasmaand plasma-treated samples, respectively.

The CPE (constant phase element), denoted as $Q$ in the equivalent circuit, is introduced instead of the pure capacitance during our simulations to obtain good agreement between the simulated and experimental data. The CPE impedance can be defined as $Z_{\mathrm{CPE}}=Y_{0}^{-1} \cdot(j \omega)^{-\mathrm{n}}$, where $Y_{0}$ is the CPE constant; $j$ is the imaginary unit $\left(j^{2}=-1\right) ; \omega$ is the angular frequency $(\omega=2 \pi f$, where $f$ is the frequency); and $\mathrm{n}$ is the exponent of the constant phase element. The CPE depends on both the $Y_{0}$ parameter and the exponent $n$. In general, $0<n<1$. When $n$ $=1$, the CPE behaves as an ideal capacitor with conventional double-layer capacitance; and when $n=0$, the CPE behaves as a resistor.

$Q_{c}$ and $Q_{c}{ }^{\prime}$ are the constant phase elements related to the coating capacitance of the non-plasma- and plasmatreated samples, respectively. $Q_{\mathrm{p}}$ and $Q_{\mathrm{ct}}$ ' are the constant phase elements related to the capacitance of the plasmatreated layer and metal charge transfer, respectively. $Z_{\mathrm{w}}$ and $Z_{\mathrm{w}}$ ' are the Warburg diffusion coefficients of the non-plasma- and plasma-treated samples, respectively.

Compared to the EIS and fitted-equivalent-circuit results, an additional capacitance $\left(Q_{p}\right)$ also occurs during the second stage after the plasma treatment and delays the water penetration and corrosion of the metal substrate, increasing the time for the coating to fail.

Since the information regarding the low frequencies in the Bode diagram mainly reflects the impedance of the coating, the impedance at low frequencies $\left(|Z|_{f=0.01}\right)$ can be used to evaluate the coating's ability to prevent corrosion. Figure 7a shows a significant peak for both the non-plasma- and plasma-treated samples; however, there is an overall declining trend of the curves. The $|Z|_{f=0.01}$ value is increased due to the covering of the pinholes by the increasing amounts of corrosion products, blocking any further infiltration of water. In addition, there is a smaller decrease in the value of $|Z|_{f=0.01}$ for the plasma-treated sample compared to the non-plasmatreated sample. The time it takes for this value to decrease to $1 \times 10^{5} \Omega \mathrm{cm}^{2}$ is also significantly longer for the plasma-treated sample compared to the non-plasmatreated sample. $R_{\mathrm{c}}$ and $R_{\mathrm{e}}$ values showed a trend similar to $|Z|_{f=0.01}$ (Figures $\mathbf{7 b}$ and 7c) and an overall decreasing trend for the curve. The $R_{\mathrm{c}}$ and $R_{\mathrm{e}}$ values for the plasma-treated samples were significantly larger than those of the non-plasma-treated samples after $100 \mathrm{~h}$. These effects may be induced by the plasma treatment, leading to the conclusion that the surface plasma treatment can delay coating failure in $3.5 \mathrm{M} \mathrm{NaCl}$ aqueous solutions.

\subsection{SKP measurements of the coating failure}

The SKP measurements of the development of coating failure for plasma- and non-plasma-treated Q235 steel with crevice AVCs are shown in Figures 8 and 9. After $13 \mathrm{~h}$ of immersion, the water permeates through the pinhole located at the center of the coating on the metal substrate and the metal substrate begins to corrode. Corrosion products accumulate over time, which reduces the potential at the center of the coatings and creates a potential difference. Based on Figures 8 and 9, we observe that the blue area at the center of the coating and the overall yellow and red area of the intact coating are significantly different. There are several successive equipotential circles from the inside to the outside. The defect located at the center of the circle is where the potential is the lowest while the outside area has a higher potential. We also observe the occurrence of the potential difference for the non-plasma-treated sample. Over time, the potential of the intact area becomes much smaller. As more water and oxygen penetrate the surface, the resistance of the coating declines and the capacity of the 
C. B. ZHENG et al.: EIS AND SKP STUDY ON IMPROVEMENT OF THE PROTECTION PERFORMANCE ...
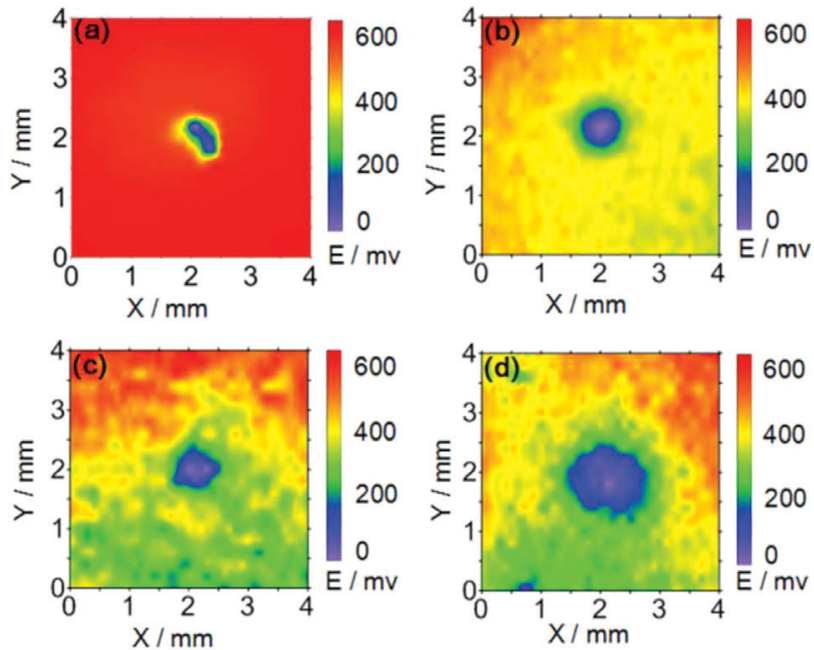

Figure 8: SKP study of the development of coating failure for non-plasma-treated Q235 steel with crevice AVCs where a, b, c and d correspond to: a) $12.5 \mathrm{~h}$, b) $26.5 \mathrm{~h}$, c) $68.5 \mathrm{~h}$ and d) $02.5 \mathrm{~h}$, respectively

coating rises. Figures $\mathbf{8 d}$ and $\mathbf{9 d}$ show that most of the coating disbonded and the potential decreased to approximately the value of the defect, indicating an absolute coating failure.

Compared to the plasma-treated sample, the expending trend of the lower potential value for the non-plasma-treated sample is significantly faster, indicating that the rate of the coating failure for the non-plasma-treated samples is higher than that of the plasma-treated samples. In addition, the lower area for the non-plasmatreated samples is larger than that of the plasma-treated samples during all the periods, demonstrating that the area of the coating failure for the non-plasma-treated samples is larger compared to the plasma-treated samples.

A sectional view of the varnish-coating-failure process without plasma treatment, at $Y=2 \mathrm{~mm}$ and at
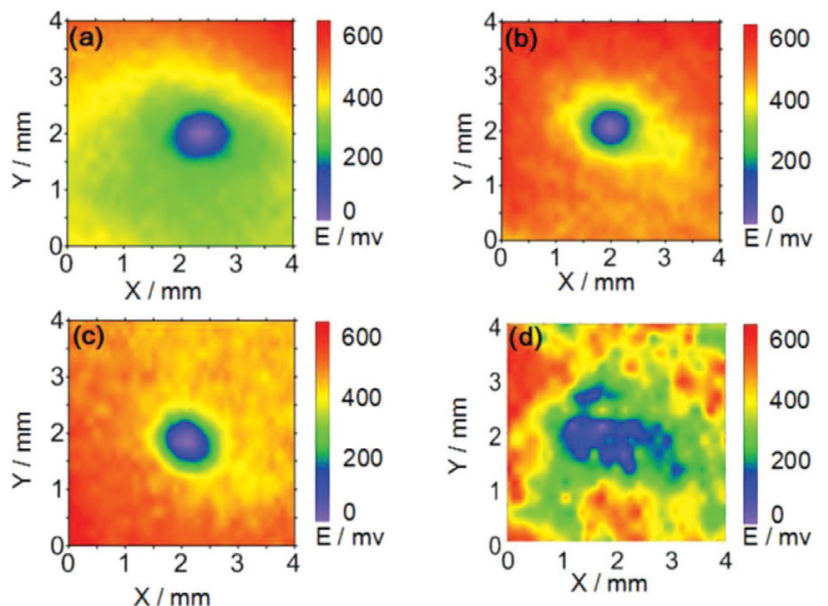

Figure 9: SKP study of the development of coating failure for plasma-treated Q235 steel with crevice AVCs where a, b, c and d correspond to: a) $13 \mathrm{~h}$, b) $36.5 \mathrm{~h}$, c) $98 \mathrm{~h}$ and d) $143 \mathrm{~h}$, respectively

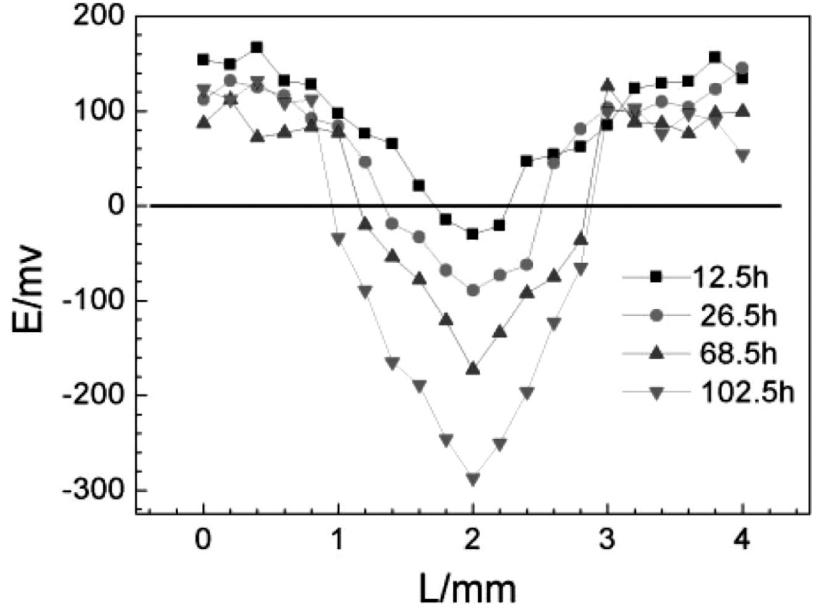

Figure 10: SKP sectional view of coating without plasma treatment at $Y=2 \mathrm{~mm}$ at different times

different times (an SKP map) is shown in Figure 10, and a sectional view of the varnish-coating-failure process with plasma treatment, at $Y=2 \mathrm{~mm}$ and at different times (an SKP map) is shown in Figure 11.

As we can see from the figure, with an increase in the time, the electric potential becomes lower and the low potential range is growing. The growth rate of the low potential region is proportional to the failure rate of the coating.

Figure 12 shows the trend chart of the change in the $\mathrm{X}$-axis length of the SKP, with the electric potential below $0 \mathrm{mV}$. It can be seen from the figure that the curve of the coating without plasma treatment is above the curve of the plasma-treated coating. It shows that the low potential range of the coating without plasma treatment is larger than that of the coating with plasma treatment. In addition, the slope of the curve of the coating without plasma treatment is larger than the slope of the curve of the coating with the plasma treatment. It also shows that the growth rate of the low electric potential without

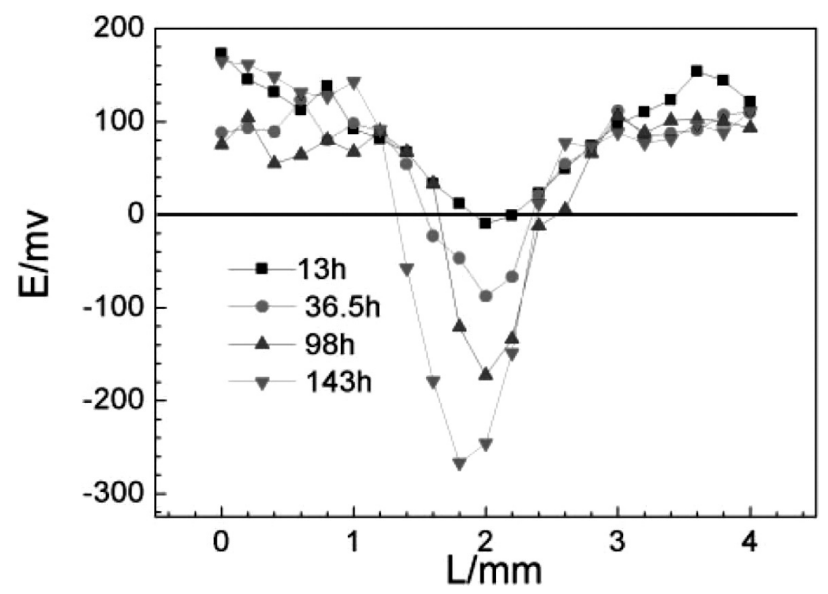

Figure 11: SKP sectional view of coating with plasma treatment at $Y=2 \mathrm{~mm}$ at different times 
C. B. ZHENG et al.: EIS AND SKP STUDY ON IMPROVEMENT OF THE PROTECTION PERFORMANCE ...

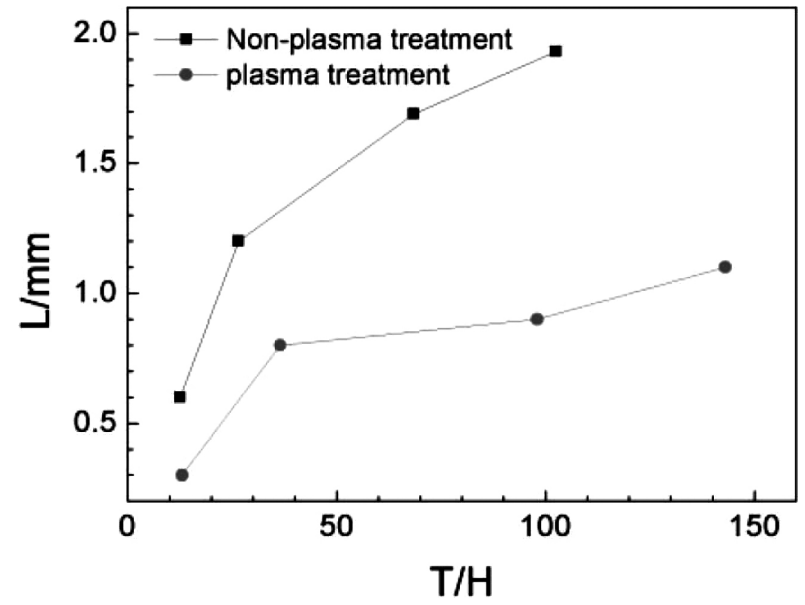

Figure 12: Trend chart of the change in the length of the SKP with the electric potential below $0 \mathrm{mV}$

plasma treatment is larger than the growth rate of the one with plasma treatment.

All of these results show that the failure rate of the plasma coating is lower than the failure rate of the coating without plasma treatment. Together, they show that the plasma treatment can delay the failure rate of the coating.

L. Yang et al. ${ }^{8}$ treated stainless-steel electrodes with air plasma and observed an increase in the relative oxygen and nitrogen contents (atom \%) of the electrodes from $3 \%$ to $17.4 \%$ and from $0 \%$ to $2.7 \%$, respectively, compared to the non-plasma-treated electrodes. V. Prysiazhnyi et al. ${ }^{25}$ treated aluminum surfaces with air plasma and observed a significant increase in the amount of -OH groups on the surfaces as well as a decrease in the surface roughness. M. A. Samad et al. ${ }^{26}$ also observed that air-plasma treatment significantly improves the adhesion between an ultra-high-molecular-weightpolyethylene (UHMWPE) film and a steel substrate by enhancing the surface energy, which in turn results in good tribological characteristics of the film. The wear life of the plasma-treated steel sample coated with the UHMWPE film increased by 10 to 12 fold compared to the untreated steel samples.

Figure 13 shows the plasma treatment process and the reaction between the alkyd resin and plasma layer. Air-plasma treatment results in connections between the metal substrates and hydroxyl(-OH), carbonyl(-CO) and other functional groups. These functional groups can react with functional groups within the alkyd resin, including $-\mathrm{C}=\mathrm{C}-$, R-OH, R-OOH, R-OOR and other functional groups. Therefore, the binding force between a metal substrate and its coating is not only due to physical adhesion but also chemical binding. ${ }^{8,25,10}$

\section{CONCLUSIONS}

Air-plasma treatment delays the failure rate of a coating and corrosion of a metal substrate under deep-
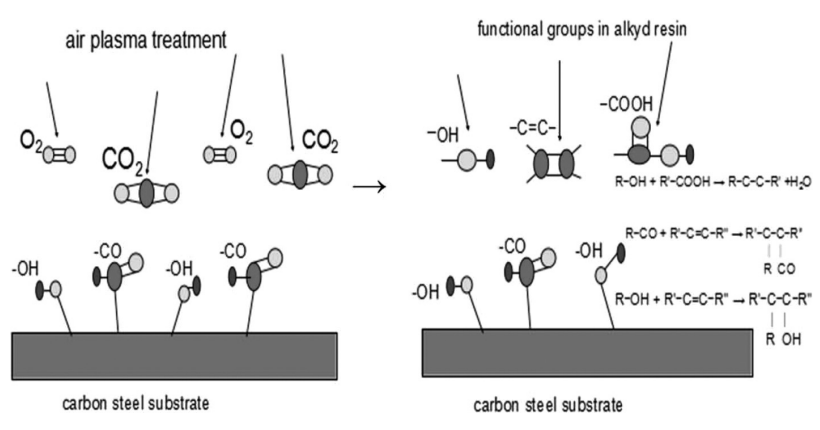

Figure 13: Air-plasma-treatment process and the reaction between the alkyd resin and plasma layer

ocean conditions. Air-plasma treatment results in connections between a metal substrate and hydroxyl(-OH), carbonyl(-CO) and other functional groups. These functional groups can react with the functional groups within the alkyd resin, including $-\mathrm{C}=\mathrm{C}-, \mathrm{R}-\mathrm{OH}, \mathrm{R}-\mathrm{OOH}$, $\mathrm{R}-\mathrm{OOR}$ and other functional groups. Therefore, the binding force between a metal substrate and its coating is due to both physical adhesion and chemical binding. EIS measurements of the plasma- and non-plasma-treated samples show the formation of an additional plasma layer/coating interface in the EC for the plasma-treated sample. The plasma-treated sample also exhibits a longer failure time and a faster decrease in the value of $|Z|_{f=0.01}$ compared to the non-plasma-treated sample under deep-ocean conditions. The air-plasma-treated sample exhibits a larger resistivity (Zre $\left.\left[\mathrm{M} \Omega<\mathrm{cm}^{2}\right]\right)$ and a longer failure time even after a four-time-longer immersion.

\section{Acknowledgements}

This paper was supported by the National Natural Science Foundation of China (No. 51401185), the Natural Science Foundation of Jiangsu Province, China (No. BK20141292), and Excellent Middle-Aged and Youth Scientist Award Foundation of Shandong Province (No. BS2014CL005).

\section{REFERENCES}

${ }^{1}$ N. Fredj, S. Cohendoz, X. Feaugas, S. Touzain, Ageing of marine coating in natural and artificial seawater under mechanical stresses, Progress in Organic Coatings, 74 (2012) 2, 391-399, doi:10.1016/ j.porgcoat.2011.10.002

${ }^{2} \mathrm{C}$. Zheng, G. Yi, Investigating the influence of hydrogen on stress corrosion cracking of 2205 duplex stainless steel in sulfuric acid by electrochemical impedance spectroscopy, Corrosion Reviews, 35 (2017) 1, 23-33, doi:10.1515/corrrev-2016-0060

${ }^{3}$ C. B. Zheng, L. Cai, Z. J. Tang, The inhibition effect of the molybdate on hydrogen permeation of 2205 duplex stainless steel, Surface \& Coatings Technology, 287 (2016) 2, 153-159, doi:10.1016/j.surfcoat. 2015.12.077

${ }^{4}$ X. Lu, X. Feng, Y. Zuo, P. Zhang, C. Zheng, Improvement of protection performance of $\mathrm{Mg}$-rich epoxy coating on AZ91D magnesium alloy by DC anodic oxidation, Progress in Organic Coatings, 104 (2017) 2, 188-198 doi:10.1016/j.porgcoat.2016. 11.001 


\section{MATERIALI IN TEHNOLOGIJE/MATERIALS AND TECHNOLOGY (1967-2017) - 50 LET/50 YEARS}

\section{B. ZHENG et al.: EIS AND SKP STUDY ON IMPROVEMENT OF THE PROTECTION PERFORMANCE ...}

${ }^{5}$ C. B. Zheng, H. K. Jiang, Y. L. Huang, Hydrogen permeation behaviour of X56 steel in simulated atmospheric environment under loading, Corrosion Engineering Science \& Technology, 46 (2011) 4, 365-367, doi:10.1179/147842209X12559428167689

${ }^{6} \mathrm{C}$. Zheng, G. Yi, Temperature effect on hydrogen permeation of X56 steel, Materials Performance, 50 (2011) 4, 72-76

${ }^{7}$ M. Schweda, T. Beck, J. Malzbender, Effect of support material creep on the delamination failure of air plasma sprayed thermal barrier coatings, Surface \& Coatings Technology, 259 (2014) 5, 543-550, doi:10.1016/j.surfcoat.2014.10.033

${ }^{8}$ L. Yang, Z. Shi, W. Yang, Enhanced capacitive deionization of lead ions using air-plasma treated carbon nanotube electrode, Surface \& Coatings Technology, 251 (2014) 29, 122-127, doi:10.1016/ j.surfcoat.2014.04.012

${ }^{9}$ X. Lu, X. Feng, Y. Zuo, C. Zheng, S. Lu, Evaluation of the micro-arc oxidation treatment effect on the protective performance of a $\mathrm{Mg}$ rich epoxy coating on AZ91D magnesium alloy, Surface \& Coatings Technology, 270 (2015) 2, 227-235, doi:10.1016/j.surfcoat.2015. 02.052

${ }^{10}$ Y. Wu, C. Han, J. Yang, Polypropylene films modified by air plasma and feather keratin graft, Surface and Coatings Technology, 206 (2011) 3, 506-510, doi:10.1016/j.surfcoat.2011.07.073

${ }^{11}$ F. Ghadami, M. H. Sohi, S. Ghadami, Effect of bond coat and post-heat treatment on the adhesion of air plasma sprayed WC-Co coatings, Surface \& Coatings Technology, 261 (2015) 2, 289-294, doi:10.1016/j.surfcoat.2014.11.016

${ }^{12}$ M. Afzal, A. N. Khan, T. B. Mahmud T. I. Khan, M. Ajmal, Effect of Laser Melting on Plasma Sprayed WC-12 wt.\%Co Coatings, Surface \& Coatings Technology, 266 (2015) 1, 22-30, doi:10.1016/ j.surfcoat.2015.02.004

${ }^{13}$ L. Yang, F. Yang, Y. Long, Y. Zhao, X. Xiong, Evolution of residual stress in air plasma sprayed yttria stabilised zirconia thermal barrier coatings after isothermal treatment, Surface \& Coatings Technology, 251 (2014) 29, 98-105, doi:10.1016/j.surfcoat.2014.04.009

${ }^{14}$ L. Wang, C. Lin, L. Yang, J. Zhang, J. Zheng, Preparation of nano/ micro-scale column-like topography on PDMS surfaces via vapor deposition: Dependence on volatility solvents, Applied Surface Science, 258 (2011) 1, 265-269, doi:10.1016/j.apsusc.2011.08.044

${ }^{15}$ C. Riccardi, R. Barni, E. Selli, G. Mazzone, M. R. Massafra, Surface modification of poly(ethylene terephthalate) fibers induced by radio frequency air plasma treatment, Applied Surface Science, 211 (2003) 4, 386-397, doi:10.1016/s0169-4332(03)00265-4

${ }^{16}$ C. B. Zheng, B. H. Yan, K. Zhang, Electrochemical investigation on the hydrogen permeation behavior of 7075-T6 Al alloy and its influence on stress corrosion cracking, International Journal of Minerals Metallurgy and Materials, 22 (2015) 7, 729-737, doi: $10.1007 / \mathrm{s} 12613-015-1128-5$
${ }^{17}$ A. E. Bolzán, L. M. Gassa, Comparative EIS study of the adsorption and electro-oxidation of thiourea and tetramethylthiourea on gold electrodes, Journal of Applied Electrochemistry, 44 (2014) 2, 279-292, doi:10.1007/s10800-013-0621-7

${ }^{18}$ R. I. Tucceri, Deactivation of poly(o -aminophenol) film electrodes by storage without use in the supporting electrolyte solution and its comparison with other deactivation processes, A study employing EIS, Journal of Applied Electrochemistry, 45 (2015) 10, 1123-1132, doi:10.1007/s10800-015-0851-y

${ }^{19}$ B. Ter-Ovanessian, C. Alemany-Dumont, B. Normand, Single frequency electrochemical impedance investigation of zero charge potential for different surface states of $\mathrm{Cu}-\mathrm{Ni}$ alloys, Journal of Applied Electrochemistry, 44 (2014) 3, 399-410, doi:10.1007/ s10800-013-0642-2

${ }^{20}$ P. P. Deshpande, N. G. Jadhav, V. J. Gelling, D. Sazou, Conducting polymers for corrosion protection: a review, Journal of Coatings Technology and Research, 11 (2014) 4, 473-494, doi:10.1007/ s11998-014-9586-7

${ }^{21}$ M. A. Domínguez-Crespo, A. M. Torres-Huerta, E. Onofre-Bustamante et al., Corrosion studies of PPy/Ni organic-inorganic hybrid bilayer coatings on commercial carbon steel, Journal of Solid State Electrochemistry, 19 (2015) 4, 1-17, doi:10.1007/s10008-0142712-8

${ }^{22}$ F. Deflorian, S. Rossi, M. D. C. Vadillo, M. Fedel, Electrochemical characterisation of protective organic coatings for food packaging, Journal of Applied Electrochemistry, 39 (2009) 11, 2151-2157, doi:10.1007/ s10800-009-9818-1

${ }^{23}$ X. Pan, J. Wu, Y. Ge, K. Xiao, H. Luo, Preparation and characterization of anticorrosion Ormosil sol-gel coatings for aluminum alloy, Journal of Sol-Gel Science and Technology, 72 (2014) 1, 8-20, doi:10.1007/s10971-014-3414-5

${ }^{24}$ R. Rajamohan, S. K. Nayaki, M. Swaminathan, A Study on HostGuest Complexation of 5-Amino-2-Mercaptobenzimidazole with $\beta$-Cyclodextrin, Journal of Solution Chemistry, 40 (2011) 5, 803, doi:10. 1007/s10953-011-9691-5

${ }^{25}$ V. Prysiazhnyi, P. Vasina, N. R. Panyala, J. Havel, M. Cemak, Air DCSBD plasma treatment of Al surface at atmospheric pressure, Surface \& Coatings Technology, 206 (2012) 12, 3011-3016, doi:10.1016/j.surfcoat.2011.12.039

${ }^{26}$ M. A. Samad, N. Satyanarayana, S. K. Sinha, Tribology of UHMWPE film on air-plasma treated tool steel and the effect of PFPE overcoat, Surface \& Coatings Technology, 204 (2010) 9, 1330-1338, doi:10.1016/j.surfcoat.2009.09.011 